\title{
Comments on First Aid for Victims of Choking An Extension of Remarks Made upon Receiving the 1986 Howland Award Acceptance of the Howland Award 1986'
}

\author{
RICHARD L. DAY \\ Department of Pediatrics, Yale University School of Medicine, New Haven, Connecticut 06520
}

Despite the fact that about 3000 Americans die each year from choking on a foreign body, research on first aid maneuvers suitable for laymen has been scarce and often faulty. None at all has been done that would apply to infants and children. This lack has led to differences of opinion concerning the relative merits of back blows and Heimlich upper abdominal thrusts (1, 2).

The American Red Cross (ARC) prepares the first aid booklets most commonly used in this country (3). Since that organization does no research, reliance for authoritative opinion is placed on the American Heart Association (AHA), the National Academy of Sciences (NAS), and the National Research Council (NRC). Committees from these groups meet jointly and feel duty bound to make judgments even in the absence of investigative data, just as a doctor may feel compelled to treat an acutely ill patient despite the lack of an immediate diagnosis. Recently there have been four laboratory style studies of choking (4-7), but they are not sufficient and provide conflicting results. Investigators should do much more, especially on the problem posed by infants and children.

For a decade Heimlich (8) has said "Back blows are death blows." His opinion is based on anecdotes of choking victims who became more obstructed after that maneuver. During roughly the same period the two small booklets distributed by the ARC have recommended four back blows between the shoulder blades, prior to four Heimlich maneuvers. As of 1986, the back blows are to be omitted (Montgomery WH, personal communication), not because of fear of them, but to simplify instructions. Infants under $1 \mathrm{yr}$ of age are still to get back blows, delivered while they are inverted and supported anteriorly by the rescuer's free arm. As will be mentioned later, such support of the chest could theoretically result in a beneficial squeeze of the chest. Research on this supposition is needed, and also on the inverted position.

Surprisingly, from 1973 through 1977, in addition to the booklets referred to above, a third set of instructions (9) was published for the ARC by Doubleday and Company which contained the following statement: "Do not allow anyone to slap you on your back if you choke, and do not try to dislodge an object from another person's throat by this means, except as a last desperate effort to save his life." The ARC was kind enough to search its archives, but found no record of data on which this advice was based. Nevertheless, it seems probable that, as Heimlich says (10), there have been others in the past with a fear of back blows.

Mittleman (11), a medical examiner, published a series of

Reprint requests Dr. William A. Silverman, 90 LaCuesta Drive, Greenbrae, CA 94904.

${ }^{1}$ Presented at the American Pediatric Society meeting, Washington, D.C., May 6, 1986. autopsies covering deaths at all ages as well as a second series on children (12). These tell of the exact site and nature of the obstructing material, but give no details of premortem events. A similar study by Weston (13), though of interest, has the same fault. It would be useful if the departments of pathology of a large number of medical centers could review their cases of suffocation death and publish the details of those cases for which an adequate premortem clinical story is available.

Two statistical studies of choking events reported by the rescuers have been published. Tables 1 and 2 summarize the results. The first is by Redding (14) who used data supplied by the AHA. In addition to the figures which appear in the table, there were scattered examples of rescues by other techniques not considered here. The Patrick (15) study contains many more case reports, and interestingly, reports results closely similar to those of the AHA. That there is a better recovery after Heimlichs than after back blows is shown by the almost invisible values for $p$ calculated for each of the sets of four numbers by the $\chi^{2}$ (see Tables 1 and 2). The permitted possible conclusions are: 1) Heimlichs are better than back blows, 2) back blows are harmful, or 3) both. To select which of these three possibilities is the truth would require more data obtained through a different approach.

The AHA interpreted their figures as supporting their official advice that four back blows should precede four Heimlichs. Patrick believed that his data showed the likelihood of a worse choking situation developing after back blows. Neither publication provides the reader with adequate details of the clinical situations which are summarized. Unfortunately, the original AHA protocols have been lost. If Patrick should publish a more detailed report, one hopes more details could be retrieved of the clinical signs and symptoms following each of the two maneuvers.

A disquieting statistical thought arises from the low death rates recorded for both studies; statements in the two texts note a rate much less than $1 \%$. One Redding/AHA table (14) leads the

Table 1. Redding-AHA-1979

\begin{tabular}{lcc}
\hline & Success & Failure \\
\hline Heimlich & 132 & 36 \\
Back blow & 53 & 56 \\
$p=0.51 \times 10^{-6}$ & & \\
\hline
\end{tabular}

Table 2. Patrick/Heimlich-1980

\begin{tabular}{lcc}
\hline & Success & Failure \\
\hline Heimlich alone or 1st & 895 & 77 \\
Heimlich after back & 137 & 55 \\
blow & & \\
$p=2.46 \times 10^{-13}$ & & \\
\hline
\end{tabular}


reader, if inclined to add up the figures, to suspect a higher mortality; however, combining the two series makes the guess of under $1 \%$ seem correct. These studies are of victims who were treated. The usual instructions tell the rescuer not to treat a victim who is able to phonate, to cough, to remain conscious, and to retain normal color of lips. If bystanders (rescuers) did indeed leave untreated someone choking with such mild symptoms fearing that harm might be done, then those that were treated and reported to Patrick and to the AHA must have been much sicker. The low death rate then becomes even more astonishing and leads to the thought that in the excitement and panic of a choking event, instructions are forgotten and everyone gets treated, pending the arrival of an ambulance.

The ideal maneuver would be one which could help to rid someone of a foreign body and which would not make matters worse. Heimlich claims these two properties for his upper abdominal thrust. Since in 1986 the official advice is for a Heimlich maneuver alone, there is no likelihood that future experience will lead to certainty as to what is best. Perhaps folk opinion will lead to a sure opinion, in the same way that over the years widespread knowledge has developed about medicinal and poisonous plants.

Pressure from a Heimlich has been studied under laboratory conditions. Heimlich (2) found that air pressure at the mouth was above $30 \mathrm{~mm} \mathrm{Hg}$ when his maneuver was performed at full inspiration and less than that at midinspiration. Day et al. (7) confirmed those results. Ruben and MacNaughton (4) and Gordon et al. (5) found only half as much pressure from Heimlichs. A reasonable explanation of the discrepancy is that the Ruben and the Gordon subjects were anesthetized and some also curarized and hence probably in a supine position or possibly at end expiration; or, lung volume had been reduced by the medications. All workers agree that a Heimlich produces a pressure wave lasting roughly $1 / 2 \mathrm{~S}$. A back blow produces a sound wave with a duration of about $1 / 50$ th $\mathrm{s}$, and hence little energy.

The results from back blows obtained by Day et al. (7) were as discrepant from the values reported by Gordon and by Ruben as were the pressures from Heimlichs. Day et al. (7) got half as much pressure from a back blow as from a Heimlich, and half as much as reported by the other workers. The medicated subjects, if really standing as reported, must have been supported in some way so that a back blow was equivalent to an intentional squeeze of the chest. If they were lying down, their position and condition would have made them very different from someone suffering from choking at a meal.

In 1986 the official advice for a 1-yr-old infant's treatment is that he be inverted and struck on the back. The rescuer's other arm is to provide support in front. Laboratory style research on this situation would be easy because the problem of informed consent could be surmounted by conducting the studies on patients with cystic fibrosis. Back blows are a standard and frequently repeated form of treatment.

Day et al. (7) studied the inertial reaction to back blows. At the suggestion of DuBois, a directional accelerometer was strapped to the outside of the neck. It was found that a blow between the shoulder blades straightened the back, thus accelerating the neck and associated structures upward, with values for $\mathrm{G}$ varying from 1.3 to 3.5 . The structures would resist with an equal force and in an opposite direction, including a piece of meat if stuck tight. If loose, the meat would appear to move down, relative to the throat. Several criticisms (18-23) of this work have betrayed a misunderstanding of the elementary physics involved. These misunderstandings make it likely that the original advocates of back blows were similarly misled, and thought a foreign body would be jolted out, in addition to being loosened as described in the written reports. (5).

\section{REFERENCES}

1. Heimlich HJ 1974 Pop goes the cafe coronary. Emerg Med 6:154

2. Heimlich HJ, Hoffman KA, Canestri FR 1975 Food choking and drowning deaths prevented by external subdiaphragmatic compression. Ann Thorac Surg 20:188

3. First Aid for Foreign Body Obstruction of the Airway. The American National Red Cross, Washington, D.C., 1976 et seq.

4. Ruben H, MacNaughton FI 1978 The treatment of food choking. Practitioner 221:725

5. Gordon AS, Belton MK, Ridolpho PE 1977 Emergency management of foreign body airway obstruction. In: Safar P (ed) Cardiopulmonary Resuscitation. Springer-Verlag, New York

6. Guildner CW, Williams D, Subitch T 1976 Airway obstructed by foreign material: the Heimlich maneuver. J Am Coll Emerg Phys 5:675

7. Day RL, Crelin ES, DuBois AB 1982 Choking: the Heimlich abdominal thrust vs back blows: an approach to measurement of inertial and aerodynamic forces. Pediatrics 70:113

8. Heimlich HJ 1979 Back blows are death blows. Emerg Med Serv 8:88

9. Standard First Aid and Personal Safety. 1973 The American National Red Cross. Doubleday \& Co., Garden City, NY

10. Heimlich HJ, Uhley MH 1979 The Heimlich maneuver. Clin Symp (CIBA) $31: 3$

11. Mittleman RE, Wetli CV 1982 The fatal cafe coronary. JAMA 247:1285

12. Mittleman RE 1984 Fatal choking in infants and children. Am J Forensic Med 5:201

13. Weston JT 1965 Airway foreign body fatalities in children. Ann Otol Laryngol $74: 1144$

14. Redding JS 1979 The choking controversy: critique of evidence on the Heimlich maneuver. Crit Care Med 7:475

15. Patrick EA 1980 Choking. J Emerg Serv 12:3

16. Eigen H 1983 Treatment of choking. Pediatrics $71: 300$

17. Day RL, DuBois AB 1983 Pediatrics $71: 300$

18. Hoffman JR 1983 Pediatrics $71: 468$

19. Day RL 1983 Pediatrics 1983; $71: 976$.

20. Greensher J, Mofenson HE 1983 Pediatrics 71:468

21. Montgomery WH 1983 Pediatrics 71:982

22. Heimlich HJ 1983 Pediatrics 71:983

23. Montgomery WH 1983 J Emerg Med Serv 12:6 